PHARMACONJurnal IImiah Farmasi - UNSRAT Vol. 9 No. 1 FEBRUARI 2020 ISSN 2302 - 2493

\title{
PROFIL PENGETAHUAN MASYARAKAT TENTANG PENGOBATAN MANDIRI (SWAMEDIKASI) DI DESA BUKAKA KECAMATAN KOTABUNAN KABUPATEN BOLAANG MONGONDOW TIMUR
}

\author{
Meilani Jayanti ${ }^{*}$, Aswin Arsyad ${ }^{2)}$ \\ ${ }^{1)}$ Program Studi Farmasi, FMIPA, Universitas Sam Ratulangi, Manado \\ 2) Jurusan Farmasi, Sekolah Tinggi Ilmu Kesehatan Muhammadiyah, Manado
}

\begin{abstract}
The effort that most done by the community to treat disease before deciding to seek help from health services or health worker is called self medication. The aim of this research is to describe the profile of community knowledge about self medication in Bukaka Village, Kotabunan subdistrict, Bolaang Mongndow Timur district. This research is an observational descriptive research which uses analytic survey method. Data collection was carried out from 165 respondents selected based on inclusion and exclusion criteria. Based on this research, it can be concluded that the profile of community knowledge about self-medication (self-medication) in Bukaka Village is still inadequate, where the percentage of community knowledge level of Bukaka Village is $36 \%$ which shows how the community's knowledge is categorized as lacking.
\end{abstract}

Keywords: Knowledge, Community, Self Medication

\begin{abstract}
ABSTRAK
Upaya yang paling banyak dilakukan oleh masyarakat untuk mengatasi keluhan, gejala penyakit, sebelum memutuskan mencari pertolongan kepada tenaga kesehatan atau sarana pelayanan kesehatan, yaitu dengan melakukan pengobatan mandiri (swamedikasi). Penelitian ini bertujuan untuk mengetahui bagaimana profil pengetahuan masyarakat Desa Bukaka Kecamatan Kotabunan Kabupaten Bolaang Mongndow Timur (boltim) tentang pengobatan mandiri (swamedikasi). Penelitian ini merupakan penelitian observasional dengan jenis penelitian deskriptif yang menggunakan metode survei analitik. Pengambilan data dilakukan terhadap 165 orang responden yang dipilih berdasarkan kriteria inklusi dan eksklusi. Berdasarkan penelitian yang telah dilakukan, dapat disimpulkan bahwa profil pengetahuan masyarakat tentang pengobatan mandiri (swamedikasi) di Desa Bukaka masih kurang dan belum memadai, dimana persentase tingkat pengetahuan masyarakat Desa Bukaka sebesar 36\% yang menunjukan bahwa tingkat pengetahuan masyarakat termasuk kategori kurang.
\end{abstract}

Kata Kunci : Pengetahuan, Masyarakat, Swamedikasi 


\section{PENDAHULUAN}

Upaya yang paling banyak dilakukan oleh masyarakat untuk mengatasi keluhan, gejala penyakit, sebelum memutuskan mencari pertolongan kepada tenaga kesehatan atau sarana pelayanan kesehatan, yaitu dengan melakukan pengobatan mandiri (swamedikasi). Pada tahun 2014, persentase masyarakat Indonesia yang melakukan swamedikasi menggunakan obat konvensional/sintetik selama satu bulan terakhir yaitu sebesar 90,54\% (BPS, 2014).

Kecenderungan swamedikasi yang masih tinggi dipengaruhi beberapa faktor, diantaranya persepsi masyarakat mengenai penyakit ringan, harga obat yang relatif lebih murah, serta kepraktisan dalam penggunaan obat-obat yang dapat digunakan untuk mengatasi penyakit ringan dengan penanganan sendiri menggunakan obat-obat yang dapat dibeli tanpa resep dokter. Faktor yang sangat berpengaruh terhadap keberhasilan terapi swamedikasi pasien yaitu perilaku swamedikasi di kalangan masyarakat (Rikomah, 2016).

Pengetahuan merupakan salah satu faktor predisposisi yang sangat penting dalam mempengaruhi terbentuknya perilaku seseorang (Pratiwi, 2014). Dalam melakukan upaya pengobatan mandiri, masyarakat membutuhkan pengetahuan yang memadai agar penentuan kebutuhan jenis dan jumlah obat dapat diambil berdasarkan alasan yang rasional. Oleh karena itu, pengetahuan mengenai pengobatan mandiri harus diperoleh dari sumber yang jelas dan dapat dipercaya.

Menurut Notoatmodjo (2003), beberapa faktor yang mempengaruhi pengetahuan yang dimiliki seseorang yaitu, pendidikan, paparan media massa, ekonomi, hubungan sosial, dan pengalaman. Berdasarkan profil Desa Bukaka (Pemerintah Desa Bukaka, 2018), masih terdapat sekitar 163 orang masyarakat Desa
Bukaka yang tidak tamat sekolah, juga hanya terdapat puskesmas pembantu dan posyandu sebagai fasilitas kesehatan desa. Dari survei awal yang dilakukan di Desa Bukaka, diketahui bahwa jarak antara desa dan fasilitas kesehatan cukup jauh, sehingga masyarakat kurang mendapat pelayanan kesehatan dan informasi obat yang kurang memadai.

Dengan demikian, perlu dilakukan penelitian untuk mengetahui bagaimana profil pengetahuan masyarakat Desa Bukaka Kecamatan Kotabunan Kabupaten Bolaang Mongndow Timur (boltim) tentang pengobatan mandiri (swamedikasi).

\section{METODOLOGI PENELITIAN}

Penelitian ini merupakan penelitian observasional dengan jenis penelitian deskriptif yang menggunakan metode survei analitik. Penelitian ini dilaksanakan di Desa Bukaka Kecamatan Kotabunan Kabupaten Bolaang Mongndow Timur, dimana waktu pengumpulan data dari responden dilakukan pada bulan September 2019. Variabel dalam penelitian ini yaitu pengetahuan responden tentang pengobatan mandiri (swamedikasi).

\section{Populasi dan Sampel}

Populasi dari penelitian ini adalah seluruh masyarakat Desa Bukaka yang berada di Dusun I dan Dusun II Kecamatan Kotabunan Kabupaten Bolaang Mongndow Timur Sulawesi Utara dengan jumlah penduduk 444 jiwa.

Sampel penelitian ini adalah sebagian masyarakat Desa Bukaka Kecamatan Kotabunan Kabupaten Bolaang Mongndow Timur yang jumlah minimal sample diperoleh dengan rumus dibawah ini (Wasis 2008):

$n=\frac{\mathrm{N}}{1+\mathrm{N}(\mathrm{d})^{2}}$ 
Keterangan:

$\mathrm{n}=$ Besar sampel

$\mathrm{N}=$ Besar Populasi (283)

$\mathrm{d}=$ Tingkat kesalahan $(5 \%)$

$n=\frac{\mathrm{N}}{1+283 \cdot(5 \%)^{2}}$

$n=\frac{283}{1+283.0,0025}$

$n=\frac{283}{1.7075}$

$n=165,7$

Pengambilan sampel dilakukan dengan menggunakan metode non random sampling dengan cara purposive sampling dimana sampel yang diambil memenuhi kriteria inklusi dan eksklusi.

Kriteria inklusi dalam penelitian ini meliputi:

a. Tercatat sebagai masyarakat Desa Bukaka kecamatan Kotabunan Kabupaten Bolaang Mongondow Timur yang ditunjukan dengan KTP (kartu tanda penduduk).

b. Berusia $\geq 17$ tahun

c. Pernah melakukan tindakan swamedikasi

d. Bisa membaca dan menulis

e. Bersedia mengisi inform consent

Kriteria eksklusi dalam penelitian ini meliputi:

a. Tidak bersedia menjadi responden penelitian

b. Tidak dapat mengingat riwayat swamedikasi

c. Tidak bisa membaca dan menulis

\section{Instrumen Penelitian}

Data penelitian ini berupa data primer. Data primer merupakan data yang diperoleh secara langsung dari responden melalui kuesioner. Pengumpulan data dalam penelitian ini dilakukan dengan menyebarkan angket (kuesioner). Data diperoleh dari hasil pengisian kuesioner yang tercantum dalam modul materi pelatihan dan peningkatan pengetahuan dan keterampilan memilih obat bagi tenaga kesehatan (Direktorat Bina Penggunaan Obat Rasional, 2008). Kuesioner tersebut terdiri dari 2 bagian, dimana bagian I dari kuesioner berisi karakteristik dari responden dan bagian II adalah pengetahuan responden dalam pengobatan sendiri. Kuesioner yang digunakan adalah kuesioner berstruktur, berisi pertanyaan-pertanyaan yang disertai sejumlah alternatif jawaban yang disediakan. Responden dalam menjawab terikat pada sejumlah kemungkinan jawaban yang sudah disediakan (Margono, 2003).

\section{Pengolahan Data}

Pada bagian I dan II, data akan diolah menggunakan teknik analisa persentase. Setelah pengumpulan data, kemudian data diolah secara sederhana dengan tabel frekuensi, kemudian diambil persentase menurut item angket. Adapun rumus persentase adalah sebagai berikut (Sibagariang, 2010):

$P=\frac{f}{n} x 100 \%$

Keterangan:

$\mathrm{P} \quad=$ Persentase

$\mathrm{f} \quad=$ Frekuensi

$\mathrm{n} \quad=$ Nilai (jumlah)

$100 \%=$ Bilangan pengali tetap

Pada bagian II dengan soal nomor $1,3,4,5,6,7,8,9$ dan 10 pertanyaan yang dijawab dengan jawaban benar atau menjawab lebih dari 3 akan diberi nilai 2, salah atau menjawab kurang dari 4 bernilai 1 dan 0 jika tidak tahu atau tidak menjawab. Data dikumpulkan dan dianalisa secara deskriptif dan disajikan dalam bentuk tabel.

Tingkat pengetahuan responden dapat dihitung berdasarkan \% pertanyaan yang dijawab benar dengan rumus: 
\% Pertanyaan dijawab benar

$=\frac{\text { Jumlah nilai yang benar }}{\text { Nilai total }} \times 100 \%$

Data yang telah dikumpulkan dari hasil kuesioner tingkat pengetahuan tersebut dapat dikategorikan dalam baik, cukup, dan kurang. Menurut Arikunto (2006), pengetahuan dibagi dalam 3 kategori, yaitu:

1. Pengetahuan baik : $76 \%-100 \%$

2. Pengetahuan cukup: $56 \%-75 \%$

3. Pengetahuan kurang: $<56 \%$

Untuk soal nomor 2 digunakan skala likert, ditabulasi dalam bentuk nilai skor, dihitung total skor untuk pertanyaan dari setiap subvariabel lalu dipersentasekan. Kriteria penilaian rata-rata tersebut menggunakan interval untuk menentukan panjang kelas interval, dimana rumus yang digunakan menurut Sudjana (2008) adalah:

Panjang kelas interval

Keterangan:

$$
=\frac{\text { Rentang }}{\text { Banyak Kelas Interval }}
$$

Rentang $=$ Nilai tertinggi - Nilai terendah

Banyak kelas interval $=4$

Panjang kelas interval $=\frac{100-0}{4}$
Nilai total

$=$ Jumlah responden $\mathrm{x}$ Jumlah soal yang di pakai $\mathrm{x} 2$
Keterangan:

$$
\begin{array}{ll}
= & \frac{100}{4} \\
= & 25
\end{array}
$$

Angka 0\%-24,99\% = Jarang

Angka 25\% - 49,99\% = kadang-kadang

Angka 50 \% -74,99\% = Sering

Angka $75 \%-100 \%=$ Selalu

\section{HASIL PENELITIAN}

Karakteristik Responden

Tabel 1. Distribusi karakteristik responden di Desa Bukaka Kecamatan Kotabunan

Kabupaten Bolaang Mongondow timur

\begin{tabular}{|l|c|c|}
\hline $\begin{array}{c}\text { Karakteristik } \\
\text { Responden }\end{array}$ & $\begin{array}{c}\text { Frekuensi } \\
(\mathbf{n = 1 6 5})\end{array}$ & $\begin{array}{c}\text { Persentase } \\
(\mathbf{\%})\end{array}$ \\
\hline Usia (tahun): & 127 & 77 \\
17-49 & 38 & 23 \\
>50 & & \\
\hline Pendidikan: & 81 & 49.1 \\
SD & 47 & 28.5 \\
SMP & 26 & 15.8 \\
SMA & 11 & 6.6 \\
PT & \\
\hline
\end{tabular}

\section{Pengetahuan Responden}

Tabel 2. Distribusi frekuensi pengetahuan rersponden tentang pengobatan mandiri di Desa Bukaka Kecamatan Kotabunan Kabupaten Bolaang Mongondow Timur

\begin{tabular}{|l|l|c|c|}
\hline No & \multicolumn{1}{|c|}{ Pertanyaan } & $\begin{array}{c}\text { Frekuensi } \\
(\mathbf{1 6 5})\end{array}$ & $\begin{array}{c}\text { Persentase } \\
(\boldsymbol{\%})\end{array}$ \\
\hline 1 & $\begin{array}{l}\text { Apakah anda mengetahui tentang penggolongan } \\
\text { obat? }\end{array}$ & 1 & \\
& 1. Golongan obat bebas & 1 & 0.6 \\
& 2. Golongan obat bebas terbatas & 0 & 0.6 \\
& 3. Golongan obat keras & 0 & 0 \\
& 4. Golongan obat psikotropik & 0 & 0 \\
& 5. Golongan obat narkotik & 2 & 1.2 \\
\cline { 2 - 4 } & Jumlah & & \\
\hline
\end{tabular}




\begin{tabular}{|c|c|c|c|}
\hline \multirow[t]{2}{*}{2} & $\begin{array}{l}\text { Apakah anda pernah memperhatikan adanya } \\
\text { tanda lingkaran berwarna pada kemasan obat? } \\
\text { 1. Selalu } \\
\text { 2. Sering } \\
\text { 3. Kadang-kadang } \\
\text { 4. Jarang } \\
\text { 5. Tidak pernah }\end{array}$ & $\begin{array}{c}0 \\
37 \\
43 \\
34 \\
51 \\
\end{array}$ & $\begin{array}{c}0 \\
22.4 \\
26 \\
20.6 \\
30.9 \\
\end{array}$ \\
\hline & Jumlah & 165 & 100 \\
\hline \multirow[t]{2}{*}{3} & $\begin{array}{l}\text { Bagaimana cara anda menanggulangi jika terjadi } \\
\text { reaksi efek samping? } \\
\text { 1. Diam saja } \\
\text { 2. Makan obar terus } \\
\text { 3. Makan obat jika ingat } \\
\text { 4. Segera periksakan ke dokter/ puskesmas/ } \\
\text { rumah sakit } \\
\text { 5. Hentikan minum obat }\end{array}$ & $\begin{array}{c}4 \\
0 \\
1 \\
117 \\
102\end{array}$ & $\begin{array}{c}1.8 \\
0 \\
0.4 \\
52.2 \\
45.5\end{array}$ \\
\hline & Jumlah & 224 & 100 \\
\hline \multirow[t]{2}{*}{4} & $\begin{array}{l}\text { Bagaimana cara penyimpanan obat di rumah } \\
\text { yang benar? } \\
\text { 1. Simpan obat di tempat yang sejuk } \\
\text { 2. Jauhkan penyimpanan obat dari sinar } \\
\text { matahari } \\
\text { 3. Jauhkan penyimpanan obat dari anak } \\
\text { 4. Simpan obat dalam kemasan aslinya } \\
\text { 5. Tidak tahu }\end{array}$ & $\begin{array}{c}150 \\
153 \\
87 \\
78 \\
7\end{array}$ & $\begin{array}{c}31.6 \\
32.2 \\
18.3 \\
16.4 \\
1.5\end{array}$ \\
\hline & Jumlah & 475 & 100 \\
\hline \multirow[t]{2}{*}{5} & $\begin{array}{l}\text { Bagaimana anda mengetahui penyebab obat } \\
\text { rusak? } \\
\text { 1. Penyimpanan yang salah } \\
\text { 2. Kadaluwarsa } \\
\text { 3. Terkena matahari langsung } \\
\text { 4. Kerusakan fisik obat } \\
\text { 5. Tidak tahu }\end{array}$ & $\begin{array}{c}31 \\
131 \\
31 \\
62 \\
12 \\
\end{array}$ & $\begin{array}{c}11.6 \\
49.1 \\
11.6 \\
23.2 \\
4.4\end{array}$ \\
\hline & Jumlah & 267 & 100 \\
\hline \multirow[t]{2}{*}{6} & $\begin{array}{l}\text { Bagaimana cara anda mengetahui bahwa obat } \\
\text { yang ada di rumah rusak? } \\
\text { 1. Adanya perubahan warna, bau, rasa } \\
\text { 2. Adanya endapan, keruh, perubahan } \\
\text { kekentalan pada sediaan obat } \\
\text { 3. Adanya perubahan bentuk obat } \\
\text { 4. Adanya kerusakan pada kemasan obat } \\
\text { 5. Tidak tahu }\end{array}$ & $\begin{array}{l}104 \\
46 \\
76 \\
75 \\
15 \\
\end{array}$ & $\begin{array}{r}32.9 \\
14.6 \\
24.1 \\
23.7 \\
4.7 \\
\end{array}$ \\
\hline & Jumlah & 316 & 100 \\
\hline 7 & $\begin{array}{l}\text { Bagaimana anda membuang obat yang sudah } \\
\text { tidak digunakan? }\end{array}$ & & \\
\hline
\end{tabular}




\begin{tabular}{|c|c|c|c|}
\hline & $\begin{array}{l}\text { 1. Dihancurkan dahulu baru dibuang } \\
\text { 2. Dibuang ke tempat sampah } \\
\text { 3. Dibuang ke got } \\
\text { 4. Dibiarkan saja } \\
\text { 5. Tidak tahu }\end{array}$ & $\begin{array}{c}22 \\
148 \\
8 \\
2 \\
4\end{array}$ & $\begin{array}{c}12 \\
80.4 \\
4.3 \\
1 \\
2.2 \\
\end{array}$ \\
\hline & Jumlah & 184 & 100 \\
\hline \multirow[t]{2}{*}{8} & $\begin{array}{l}\text { Bagaimana anda membuang kemasan obat yang } \\
\text { sudah tidak digunakan? } \\
\text { 1. Dihancurkan dahulu baru dibuang } \\
\text { 2. Dibuang ke tempat sampah } \\
\text { 3. Dibuang ke got } \\
\text { 4. Disimpan agar dapat digunakan kembali } \\
\text { 5. Tidak tahu }\end{array}$ & $\begin{array}{c}16 \\
152 \\
6 \\
1 \\
2\end{array}$ & $\begin{array}{c}9 \\
85.9 \\
3.4 \\
0.6 \\
1.1\end{array}$ \\
\hline & Jumlah & 177 & 100 \\
\hline \multirow[t]{2}{*}{9} & $\begin{array}{l}\text { Apabila ada tanda } \text { (lingkaran hitam dasar } \\
\text { biru) pada kemasan obat, artinya obat tersebut } \\
\text { termasuk golongan? } \\
\text { 1. Golongan obat narkotika } \\
\text { 2. Golongan obat psikotropika } \\
\text { 3. Golongan obat keras } \\
\text { 4. Golongan obat bebas } \\
\text { 5. Golongan obat bebas terbatas }\end{array}$ & $\begin{array}{l}0 \\
0 \\
0 \\
0 \\
0\end{array}$ & $\begin{array}{l}0 \\
0 \\
0 \\
0 \\
0\end{array}$ \\
\hline & Jumlah & 0 & 0 \\
\hline \multirow[t]{2}{*}{10} & $\begin{array}{l}\text { Di dalam brosur terdapat informasi tentang } \\
\text { kontraindikasi yang artinya? } \\
\text { 1. Takaran minum obat } \\
\text { 2. Cara minum obat } \\
\text { 3. Cara menyimpan obat } \\
\text { 4. Efek samping obat } \\
\text { 5. Keadaan pasien yang tidak boleh minum obat } \\
\text { tertentu }\end{array}$ & $\begin{array}{l}0 \\
0 \\
0 \\
0 \\
2\end{array}$ & $\begin{array}{c}0 \\
0 \\
0 \\
0 \\
1.2\end{array}$ \\
\hline & Jumlah & 2 & 1.2 \\
\hline
\end{tabular}

Tabel 3. Distribusi Jawaban Terhadap Subvariabel Pengetahuan

\begin{tabular}{cccccccccccccc}
\hline \multirow{2}{*}{$\begin{array}{c}\text { butir } \\
\text { soal }\end{array}$} & \multicolumn{2}{c}{1} & \multicolumn{2}{c}{2} & \multicolumn{2}{c}{3} & \multicolumn{2}{c}{4} & & 5 & \multicolumn{2}{c}{ jumlah } \\
\cline { 2 - 14 } & Jwb & skor & jwb & Skor & jwb & skor & Jwb & skor & Jwb & Skor & $\begin{array}{c}\text { Jw } \\
\text { b }\end{array}$ & skor \\
\hline 1 & 1 & 1 & 1 & 1 & 0 & 0 & 0 & 0 & 0 & 0 & 2 & 2 \\
\hline 3 & 105 & 105 & 60 & 60 & 0 & 0 & 0 & 0 & 0 & 0 & 165 & 165 \\
\hline 4 & 6 & 6 & 55 & 55 & 41 & 41 & 59 & 118 & 0 & 0 & 161 & 220 \\
\hline 5 & 83 & 83 & 60 & 60 & 9 & 9 & 9 & 18 & 0 & 0 & 161 & 170 \\
\hline 6 & 66 & 66 & 52 & 52 & 12 & 12 & 27 & 54 & 0 & 0 & 157 & 184 \\
\hline
\end{tabular}




\begin{tabular}{ccccccccccccc}
\hline 7 & 145 & 145 & 20 & 20 & 0 & 0 & 0 & 0 & 0 & 0 & 165 & 165 \\
\hline 8 & 151 & 151 & 13 & 13 & 0 & 0 & 0 & 0 & 0 & 0 & 164 & 164 \\
\hline 9 & 0 & 0 & 0 & 0 & 0 & 0 & 0 & 0 & 0 & 0 & 0 & 0 \\
\hline 10 & 2 & 2 & 0 & 0 & 0 & 0 & 0 & 0 & 0 & 0 & 2 & 2 \\
\hline JMLH & 559 & 559 & 261 & 261 & 62 & 62 & 95 & 190 & 0 & 0 & 997 & 1,072 \\
\hline
\end{tabular}

Nilai total $=$ Jumlah responden $\mathrm{x}$ Jumlah soal yang di pakai $\mathrm{x} 2$

$$
\begin{aligned}
\% \text { Pertanyaan dijawab benar }= & \frac{\text { Jumlah nilai yang benar }}{\text { Nilai total }} \times 100 \% \\
& =\frac{1,072}{2970} \times 100 \% \\
& =0,36 \times 100 \% \\
& =36 \%
\end{aligned}
$$

Tabel 4. Distribusi Jawaban Terhadap Subvariabel Pengetahuan

\begin{tabular}{cccccccccccccc}
\hline \multirow{2}{*}{$\begin{array}{c}\text { butir } \\
\text { soal }\end{array}$} & \multicolumn{2}{c}{1} & \multicolumn{2}{c}{2} & \multicolumn{2}{c}{3} & \multicolumn{2}{c}{4} & \multicolumn{2}{c}{5} & \multicolumn{2}{c}{ jumlah } \\
\cline { 2 - 15 } & Jwb & skor & jwb & Skor & Jwb & $\begin{array}{c}\text { Sko } \\
\text { r }\end{array}$ & Jwb & skor & jwb & skor & jwb & skor \\
\hline 2 & 0 & 0 & 37 & 111 & 43 & 86 & 34 & 34 & 51 & 0 & 165 & 231 \\
\hline JMLH & 0 & 0 & 37 & 111 & 43 & 86 & 34 & 34 & 51 & 0 & 165 & 231 \\
\hline
\end{tabular}

Nilai total $=$ Jumlah responden $\mathrm{x}$ Jumlah soal yang di pakai $\mathrm{x} 2$

$$
\begin{aligned}
\% \text { Pertanyaan dijawab benar }= & \frac{\text { Jumlah nilai yang benar }}{\text { Nilai total }} \times 100 \% \\
& =\frac{231}{1320} \times 100 \% \\
& =0,175 \times 100 \% \\
& =17,5 \%
\end{aligned}
$$

\section{PEMBAHASAN}

Penelitian ini dilakukan di Desa Bukaka Kecamatan Kotabunan, Kabupaten Bolaang Mongondow Timur, Provinsi Sulawesi Utara. Berdasarkan profil Desa Bukaka, Jumlah penduduk desa yang tercatat pada tahun 2018 sebanyak 450 jiwa dengan jumlah penduduk yang berusia 17 tahun keatas tercatat sebanyak 283 jiwa. Pekerjaan yang dilakukan mayoritas masyarakat Desa Bukaka adalah sebagai petani.

Pengambilan data dilakukan terhadap 165 orang responden yang dipilih berdasarkan kriteria inklusi dan eksklusi. Hasil kuesioner mengenai karakteristik responden (Tabel 1) menunjukkan bahwa, sebanyak 127 orang atau $77 \%$ responden berusia 17-49 tahun, dan sebanyak 38 orang atau $23 \%$ responden berusia 50 tahun keatas. 
Tingkat pendidikan dari responden menunjukkan bahwa sebanyak 81 orang atau $49.1 \%$ responden adalah lulusan SD, 47 orang atau $28.5 \%$ responden adalah lulusan SMP, 26 orang atau $15.8 \%$ responden adalah lulusan SMA, dan 11 orang atau $6.6 \%$ responden adalah lulusan perguruan tinggi.

Kuesioner yang dibagikan kepada responden memberikan beberapa alternatif jawaban, dimana responden dapat menjawab lebih dari satu jawaban yang tersedia, juga diperkenankan untuk tidak menjawab jika responden tidak mengetahui jawabannya. Berdasarkan hasil kuesioner pada Tabel 2, diperoleh 2 orang atau $1.2 \%$ responden yang dapat menjawab pertanyaan tersebut dan 163 orang atau $98.8 \%$ responden tidak menjawab. Hal ini dikarenakan responden tidak paham tentang golongan obat, sehingga tingkat pengetahuan dari masyarakat kurang.

Frekuensi masyarakat dalam memperhatikan adanya tanda lingkaran berwarna pada kemasan obat juga cukup beragam. Hasil yang diperoleh dari jawaban responden menunjukkan bahwa, sebanyak 37 orang atau $22.4 \%$ responden menjawab sering, 43 orang atau $26 \%$ responden menjawab kadang-kadang, 34 orang atau $20.6 \%$ responden menjawab jarang, dan 51 orang atau $30.9 \%$ responden menjawab tidak pernah. Hal ini dapat dikarenakan banyak responden tidak mengetahui penggolongan obat, sehingga responden mengganggap tanda lingkaran tidak begitu penting.

Pengetahuan responden mengenai cara menanggulangi reaksi efek samping obat diperoleh hasil bahwa 117 orang atau 52.2\% responden memilih untuk segera memeriksakan diri ke dokter dan 102 orang atau $45.5 \%$ responden memilih untuk menghentikan minum obat. Hasil tersebut menunjukkan bahwa ada responden yang memilih lebih dari 1 jawaban, dimana jawaban tersebut adalah benar. Oleh karena itu, responden dianggap cukup paham mengenai cara menanggulangi reaksi efek samping obat.

Pengetahuan responden mengenai cara penyimpanan obat di rumah yang benar diperoleh hasil bahwa sebanyak 150 orang atau $31.6 \%$ responden menyimpan obat di tempat sejuk, 153 orang atau $32.2 \%$ responden menjauhkan dari sinar matahari, 87 orang atau $18.3 \%$ responden menjauhkannya dari anak, 78 orang atau $16.4 \%$ responden menyimpan dalam kemasan aslinya. Dengan demikian, dapat diketahui bahwa sebagian besar responden (98.5\%) dapat menjawab dengan benar, dan 7 orang atau $1.5 \%$ responden tidak mengetahui jawabannya. Hal ini menunjukkan bahwa responden sudah mengetahui mengenai cara penyimpanan obat di rumah yang benar.

Pengetahuan responden mengenai penyebab obat rusak, diperoleh hasil bahwa 131 orang atau $49.1 \%$ responden menjawab kadaluwarsa, 31 orang atau $11.6 \%$ responden menjawab penyimpanan yang salah, hasil yang sama juga untuk jawaban terkena matahari langsung, dan sebanyak 62 orang atau $23.2 \%$ responden menjawab kerusakan fisik obat. Dengan demikian, dapat diketahui bahwa sebagian besar responden $(95.6 \%)$ dapat menjawab dengan benar, dan 12 orang atau $4.4 \%$ responden tidak mengetahui jawabannya. Hal ini menunjukkan bahwa responden sudah mengetahui mengenai penyebab obat rusak.

Pengetahuan responden mengenai obat rusak diperoleh hasil bahwa 104 orang atau $32.9 \%$ responden menjawab adanya perubahan warna, bau, rasa, 76 orang atau $24.1 \%$ responden menjawab adanya perubahan bentuk obat, 75 orang atau $23.7 \%$ responden menjawab adanya kerusakan pada kemasan obat, dan 46 orang atau 14.6\% responden menjawab adanya endapan, keruh, perubahan kekentalan pada sediaan 
obat. Sedangkan sebanyak 15 orang atau $4.7 \%$ responden tidak mengetahui jawabannya. Hal ini menunjukkan bahwa pengetahuan responden mengenai obat rusak masih belum memadai.

Pengetahuan responden mengenai cara membuang obat dan kemasan obat yang sudah tidak digunakan diperoleh hasil bahwa 148 orang atau $80.4 \%$ responden membuang obat ke tempat sampah dan 152 orang atau $85.9 \%$ responden membuang kemasan obat di tempat sampah. Hal ini menunjukkan bahwa pengetahuan responden mengenai cara membuang obat dan kemasan yang sudah tidak digunakan masih belum memadai.

Pengetahuan responden mengenai tanda lingkaran pada kemasan obat diperoleh hasil bahwa tidak ada responden yang mengetahui jawabannya. Hal ini menunjukkan bahwa pengetahuan responden mengenai penggolongan obat dan tanda obat di kemasan masih kurang. Hasil yang hampir sama diperoleh dari pengetahuan mengenai kontraindikasi obat, dimana 2 orang atau $1.2 \%$ responden mengetahui jawaban yang benar, sedangkan responden yang lain tidak mengetahui jawabannya. Hal ini menunjukkan bahwa pengetahuan responden mengenai penggolongan obat dan tanda obat di kemasan masih kurang.

Berdasarkan hasil kuesioner yang dibagikan kepada responden mengenai profil pengetahuan masyarakat tentang pengobatan mandiri (swamedikasi) menunjukkan bahwa persentase tingkat pengetahuan masyarakat Desa Bukaka sebesar 36\%, dimana hasil tersebut termasuk dalam kategori kurang. Disamping itu, tingkat pendidikan masyarakat yang masih tergolong rendah menyebabkan masyarakat kurang cepat memahami informasi yang diberikan.

\section{KESIMPULAN}

Berdasarkan penelitian yang telah dilakukan, dapat disimpulkan bahwa profil pengetahuan masyarakat tentang pengobatan mandiri (swamedikasi) di Desa Bukaka masih kurang dan belum memadai, dimana persentase tingkat pengetahuan masyarakat Desa Bukaka sebesar 36\% yang menunjukan bahwa tingkat pengetahuan masyarakat termasuk kategori kurang.

\section{SARAN}

Disarankan bagi masyarakat untuk lebih aktif mencari informasi mengenai pengobatan yang bisa dilakukan sendiri (swamedikasi) dari sumber yang jelas dan terpercaya. Penelitian lanjutan dapat dilakukan dengan memperluas subjek penelitian dan melakukan intervensi dalam penelitian.

\section{DAFTAR PUSTAKA}

Anonim. 2018. Profil Desa Bukaka. Pemerintah Desa Bukaka

Arikunto, S. 2010. Prosedur Penelitian Suatu Pendekatan Praktik. Jakarta: Rineka Cipta.

Direktorat Bina Penggunaan Obat Rasional. 2008. Materi Pelatihan Peningkatan Pengetahuan dan Keterampilan Memilih Obat Bagi Tenaga Kesehatan. Depkes RI: Jakarta

Margono, S. 2003. Metodologi Penelitian Pendidikan. Rineka Cipta: Jakarta

Notoatmodjo. 2003. Pendidikan dan perilaku kesehatan. Rineka Cipta: Jakarta

Pratiwi, Pristianty, L., Noorrizka, G., dan Impian, A., 2014. Pengaruh Pengetahuan Terhadap Perilaku Swamedikasi Obat Anti-Inflamasi Non-Steroid Oral Pada Etnis 
PHARMACONJurnal IImiah Farmasi - UNSRAT Vol. 9 No. 1 FEBRUARI 2020 ISSN 2302 - 2493

Thionghoa Di Surabaya. Jurnal Farmasi Komunitas, 1(2): 36- 40.

Rikomah, S. E. 2016. Farmasi Klinik. Edisi 1. Deepublish: Yogyakarta. hal. 16, 168.

Sibagariang, E.E. 2010. Metodologi Penelitian untuk Mahasiswa
Diploma Kesehatan. Trans Info Media: Jakarta

Sudjana. 2008. Metode Statistika. Tarsito: Bandung

Wasis. 2008. Pedoman Riset Praktis untuk profesi perawat. EGC: Jakarta 